\title{
Seroepidemiology of Reovirus in Healthy Dogs in Six Prefectures in Japan
}

\author{
Chung Chew HWANG ${ }^{1}$, Masami MOCHIZUKI ${ }^{2}$, Ken MAEDA ${ }^{3)}$, Masaru OKUDA ${ }^{1,4,5)}$ and Takuya MIZUNO ${ }^{1,4,5) *}$ \\ 1)Laboratory of Veterinary Internal Medicine, The United Graduate School of Veterinary Science, Yamaguchi University, \\ 1677-1 Yoshida, Yamaguchi 753-8515, Japan \\ ${ }^{2)}$ Emerging Infectious Diseases, Joint Faculty of Veterinary Medicine, Kagoshima University, 1-21-24 Korimoto, Kagoshima \\ 890-0065, Japan \\ 3) Laboratory of Veterinary Microbiology, Joint Faculty of Veterinary Medicine, Yamaguchi University, 1677-1 Yoshida, Yamaguchi \\ 753-8515, Japan \\ ${ }^{4)}$ Laboratory of Veterinary Internal Medicine, Joint Faculty of Veterinary Medicine, Yamaguchi University, 1677-1 Yoshida, \\ Yamaguchi 753-8515, Japan \\ ${ }^{5)}$ Biomedical Science Center for Translational Research, The United Graduate School of Veterinary Science, Yamaguchi University, \\ 1677-1 Yoshida, Yamaguchi 753-8515, Japan
}

(Received 25 September 2013/Accepted 13 November 2013/Published online in J-STAGE 27 November 2013)

ABSTRACT. Reovirus infection is common in mammals. However, seroepidemiological data of reovirus neutralizing antibodies are limited in dogs. In this study, sera of 65 healthy dogs from six prefectures across Japan were tested for neutralizing antibodies against reovirus serotype 1 strain Lang (T1L), serotype 2 strain Amy (T2A) and serotype 3 strain Dearing (T3D) using plaque reduction neutralization test (PRNT). Seropositivity against reovirus T1L, T2A and T3D was 53.85\%, 33.85\% and 46.15\%, respectively. Distribution of reovirus seropositive samples displayed no distinguishable geographical pattern. However, reovirus seropositivity increased with age and in dogs housed outdoor. Co-infection of multiple reovirus serotypes in dogs was also detected. These data will provide valuable insights towards the usage of reovirus in oncolytic virotherapy in canine cancers.

KEY WORDS: canine, neutralizing antibody, plaque reduction neutralization test, reovirus, seroepidemiology.

doi: 10.1292/jvms.13-0472; J. Vet. Med. Sci. 76(3): 471-475, 2014

Reovirus is a small, non-enveloped icosahedral virus with 10 segments of double stranded RNA genome, belonging to the genus Orthoreovirus within the family Reoviridae [26]. Reovirus is ubiquitous in geographical distribution and has the capacity to infect nearly every known mammalian species, including humans and dogs [23]. However, as a single agent, reovirus rarely causes clinical disease. Upper respiratory or gastrointestinal symptoms are among the possible manifestations of reovirus infection in young and adult animals $[9,11,16]$. Reovirus has also been reported to be one of the aetiologies of kennel cough [3].

Seroepidemiological surveys of reovirus in healthy humans revealed that the incidence of seropositivity rises from approximately $35 \%$ in early childhood, to approximately $60 \%$ in teenage years and more than $85 \%$ in late adulthood $[10,28,29]$. However, unlike in humans, seroepidemiological data of reovirus in healthy dogs are limited. Reports have indicated that $14-63 \%$ of sampled dog populations have an elevated reovirus neutralizing antibody titer $[5,6,17,19]$. Even though isolation of various serotypes of reovirus from

*Correspondence to: Mizuno, T., Laboratory of Veterinary Internal Medicine, Joint Faculty of Veterinary Medicine, Yamaguchi University, 1677-1 Yoshida, Yamaguchi 753-8515, Japan. e-mail:mizutaku@yamaguchi-u.ac.jp

(C)2014 The Japanese Society of Veterinary Science

This is an open-access article distributed under the terms of the Creative Commons Attribution Non-Commercial No Derivatives (by-ncnd) License $<$ http://creativecommons.org/licenses/by-nc-nd/3.0/ $>$. dogs and cats has been reported, it is usually incidental [2, $4,9,11,13,14,16,27]$. Alternatively, reovirus infection can be detected, and reovirus serotypes are distinguishable by means of the capacity of reovirus neutralizing antibodies to neutralize viral infectivity and inhibit hemagglutination (HA) $[22,25]$. Reovirus neutralization and HA activities are restricted to a single reovirus gene segment, $\mathrm{S} 1$, that encodes for the $\sigma 1$ and $\sigma 1 \mathrm{~s}$ proteins [32].

The usage of reovirus serotype 3 strain Dearing (T3D) has already reached phase II and III clinical trials in a range of human cancers [12], and our laboratory is exploring the feasibility of reovirus T3D in canine cancers [8]. It has been reported that the dramatic increment of reovirus neutralizing antibody titer hampers the efficiency of intravenous reovirus therapy in human cancer patients [33]. Therefore, reovirus neutralizing antibodies due to natural infection may also interfere with reovirus therapy. This emphasizes the importance of seroepidemiological data of reovirus in the dog population in order to allow a sound prediction of the effects of therapy using reovirus in canine cancer patients.

This study focused on the seroepidemiological survey of reovirus serotype 1 strain Lang (T1L), serotype 2 strain Amy (T2A) and serotype 3 strain Dearing (T3D) in healthy dogs from six prefectures across Japan, namely Hokkaido, Tokyo, Aichi, Osaka, Yamaguchi and Fukuoka. Reovirus seropositive samples were also analyzed according to age groups, housing environment and co-infectivity of reovirus serotypes.

Mouse L929 fibroblastic cell line was used throughout the study. The cell line was obtained from the Cell Resource 
Table 1. Summary of reovirus neutralizing antibody titers in dogs in 6 prefectures in Japan

\begin{tabular}{|c|c|c|c|c|c|c|c|c|c|c|}
\hline \multirow{2}{*}{\multicolumn{2}{|c|}{$\begin{array}{l}\text { Serotypes of } \\
\text { reovirus }\end{array}$}} & \multicolumn{8}{|c|}{ Neutralizing antibody titer } & \multirow{2}{*}{ Total } \\
\hline & & $<20$ & 20 & 40 & 80 & 160 & 320 & 640 & 1,280 & \\
\hline \multirow{2}{*}{ T1L } & No. of samples & 30 & 5 & 9 & 8 & 6 & 2 & 3 & 2 & 65 \\
\hline & $\%$ & 46.15 & 7.69 & 13.85 & 12.31 & 9.23 & 3.08 & 4.62 & 3.08 & 100.00 \\
\hline \multirow{2}{*}{$\mathrm{T} 2 \mathrm{~A}$} & No. of samples & 43 & 5 & 3 & 4 & 3 & 7 & 0 & 0 & 65 \\
\hline & $\%$ & 66.15 & 7.69 & 4.62 & 6.15 & 4.62 & 10.77 & 0.00 & 0.00 & 100.00 \\
\hline \multirow{2}{*}{ T3D } & No. of samples & 35 & 9 & 5 & 6 & 3 & 2 & 5 & 0 & 65 \\
\hline & $\%$ & 53.85 & 13.85 & 7.69 & 9.23 & 4.62 & 3.08 & 7.69 & 0.00 & 100.00 \\
\hline
\end{tabular}

a) Samples are considered as reovirus seropositive when reovirus neutralizing antibody titer is 20 or greater.

(A)

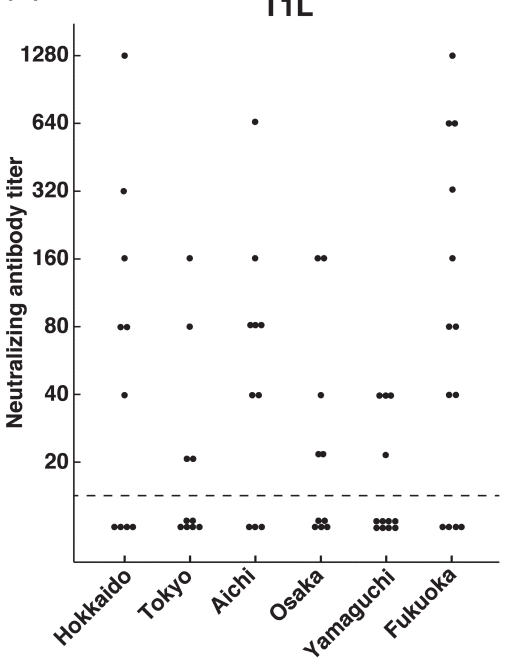

(B)

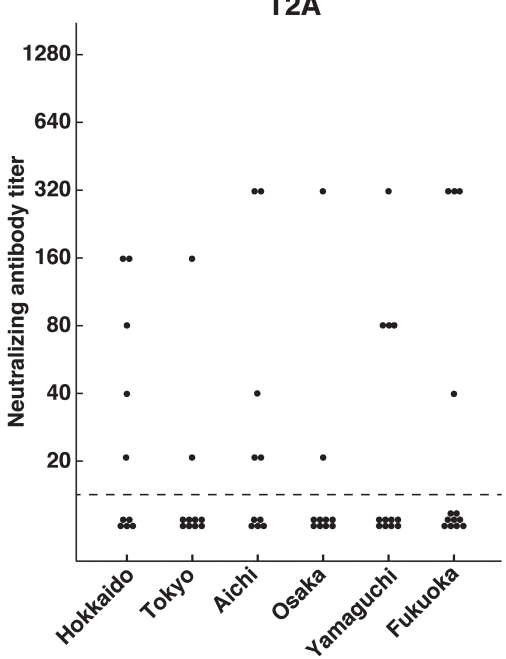

(C)

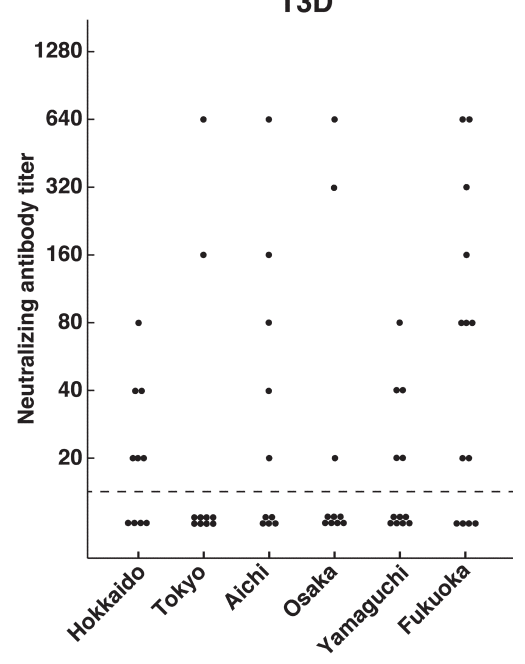

Fig. 1. Distributions of neutralizing antibody titers against reovirus T1L (A), T2A (B) and T3D (C) in Hokkaido, Tokyo, Aichi, Osaka, Yamaguchi and Fukuoka. Samples are considered as reovirus seropositive when reovirus neutralizing antibody titer is 20 or greater.

Center for Biomedical Research (Institute of Development, Aging and Cancer, Tohoku University, Sendai, Japan) and maintained in R10 complete medium (RPMI1640 supplemented with $10 \%$ FBS, $100 \mathrm{U} / \mathrm{m} l$ penicillin, $100 \mu \mathrm{g} / \mathrm{m} l$ streptomycin and $55 \mu \mathrm{M} 2$-mercaptoethanol) kept at $37^{\circ} \mathrm{C}$ in a humidified $5 \% \mathrm{CO}_{2}$ incubator. Reovirus T1L and T2A are stock viruses in our laboratory, while reovirus T3D was from Dr. Patrick W. K. Lee through Dr. Tsuyoshi Etoh (Oita University, Japan). All three serotypes of reovirus were propagated in L929 cells grown in RPMI1640 without FBS. Supernatant of the infected cells was collected when cytopathic effect was observed in $80 \%$ of the cells. Viral titer was determined by plating the viral supernatant onto susceptible L929 cell monolayer using plaque titration method as previously described [1]. Briefly, virus was diluted serially and $200 \mu l$ of each dilution added to wells in 6-well plates. After absorption for $1 \mathrm{hr}$ at $37^{\circ} \mathrm{C}$, the cells were overlaid with $2 \mathrm{ml}$ of RPMI1640 containing 0.8\% Seaplaque Agarose (Lonza, Rockland, ME, U.S.A.) and antibiotics without FBS. After 6 days of incubation at $37^{\circ} \mathrm{C}$ in a humidified $5 \% \mathrm{CO}_{2}$ incubator, plaques were fixed with $10 \%$ formalin and stained with crystal violet before being counted.

Serum was collected from a total of 65 healthy dogs that came to veterinary clinics for routine health checks in six prefectures (Hokkaido, Tokyo, Aichi, Osaka, Yamaguchi and Fukuoka) in Japan in 2006 . All sera were stored at $-20^{\circ} \mathrm{C}$ and inactivated at $56^{\circ} \mathrm{C}$ for $30 \mathrm{~min}$ prior to plaque reduction neutralization test (PRNT). A minimum of 10 samples from each prefecture were used in this study. PRNT was performed using L929 cell monolayer as previously described [32] with modifications. To screen for reovirus seropositive samples, sera were diluted at 1:20, and 60 PFUs of reovirus was mixed before incubation for $1 \mathrm{hr}$ at $37^{\circ} \mathrm{C}$. Next, the mixtures were incubated with the L929 cell monolayer for another $\mathrm{hr}$ at $37^{\circ} \mathrm{C}, 5 \% \mathrm{CO}_{2}$. Finally, the mixtures were removed before RPMI1640 containing 0.8\% Seaplaque Agarose and antibiotics without FBS was layered onto the cells and incubated for 6 days. Plaques were fixed with $10 \%$ formalin and stained with crystal violet before being counted. Sera that reduce greater than $80 \%$ of plaques were considered positive for reovirus neutralizing antibodies [32]. Sera that were positive for reovirus neutralizing antibodies were selected, and PRNT was repeated with dilutions of serum up to $1: 10,240$ to determine the maximum antibody titer.

Frequency distributions of neutralizing antibody titers against reovirus T1L, T2A and T3D are shown in Table 1. Al- 
(A)

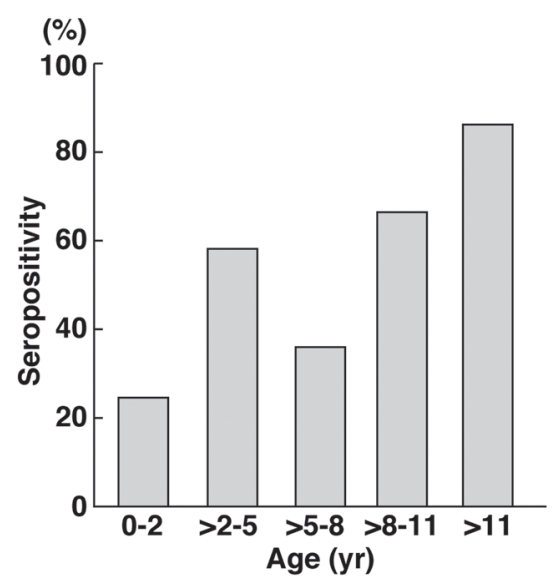

(B)

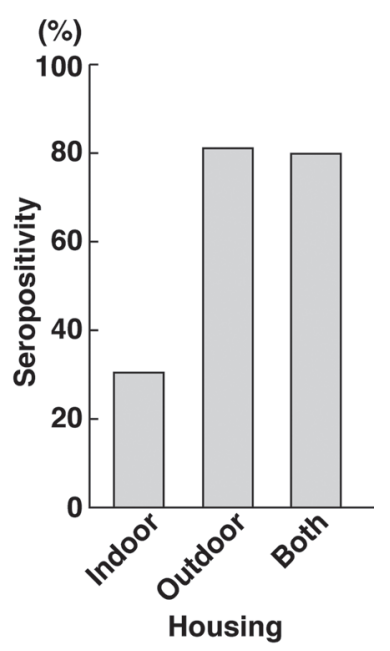

Fig. 2. Percentage of reovirus seropositivity according to age groups (A) and housing environment (B). Samples are considered as reovirus seropositive, if they are seropositive for any one of the reovirus serotypes. Reovirus seropositive samples have reovirus neutralizing antibody titer of 20 or greater.

(A)

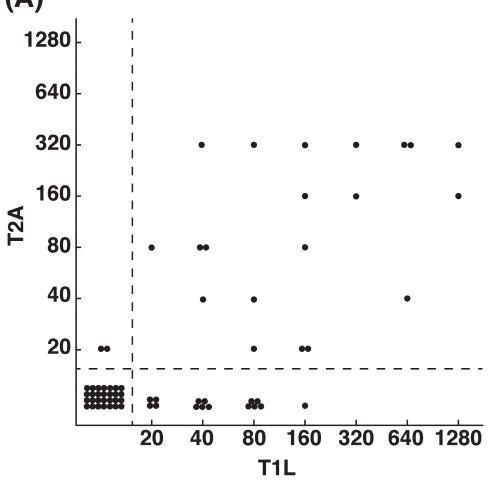

(B)

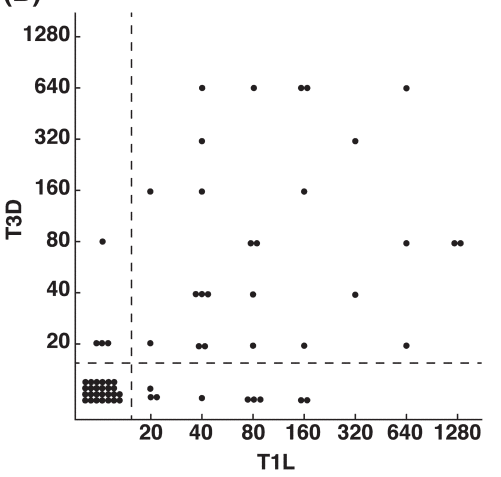

(C)

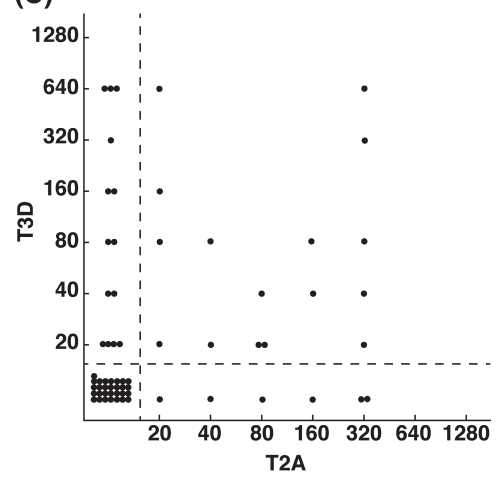

Fig. 3. Co-infection of reovirus T1L and T2A (A), T1L and T3D (B) and T2A and T3D (C). Samples are considered as reovirus seropositive when reovirus neutralizing antibody titer is 20 or greater.

most half of the samples did not have neutralizing antibodies against reovirus T1L, T2A and T3D. There was no obvious difference between the frequencies of reovirus seropositivity among the 3 serotypes of reovirus. This indicates that reovirus infection is widely spread in the sampled dog population regardless of serotype. Distributions of reovirus seropositive samples in each of the six prefectures across Japan were also analyzed. However, there was an uneven distribution of reovirus neutralizing antibody titers with no distinguishable pattern in those prefectures (Fig. 1). Although the number of samples was limited, this suggests that reovirus is prevalent in the six prefectures involved in this study.

Next, we investigated the correlation of reovirus seropositivity in various age groups and housing environment of the sampled canine population. There was a trend in reovirus seropositivity according to age groups (Fig. 2A). The number of reovirus seropositive samples in young dogs (less than two years) was comparatively lower than old dogs (more than 11 years). This finding is consistent with a report of reovirus seropositivity in humans [28], where the percentage of reovirus seropositivity rises due to increased exposure to reovirus in later parts of life. The housing environment of dogs also correlated with the number of reovirus seropositive samples (Fig. 2B). In comparison to dogs housed indoor, dogs housed outdoor or in both environments had a higher percentage of reovirus seropositivity. As reovirus is commonly isolated from contaminated water sources $[15,18$, 30], dogs housed outdoor are prone to exposure to reovirus. This result coincides with a report where a higher percentage of stray dogs were found to be reovirus seropositive [6]. 
In order to detect the co-infection of reovirus serotypes in the sampled population, we created three comparison groups (T1L vs. T2A; T1L vs. T3D; T2A vs. T3D) (Fig. 3 ). More than a quarter of the samples in all groups were seropositive for 2 reovirus serotypes. Out of the 65 sera, 15 were also seropositive for all 3 reovirus serotypes. This finding indicates that reovirus neutralizing antibodies of one serotype do not provide immunity towards reovirus infection of another serotype. Hence, reovirus infection of more than one serotype can still occur depending on exposure. Similar trends of reovirus infection of multiple serotypes have been previously reported in healthy dogs [6, 17, 19], cattle [24], swine [7] and humans [20, 21, 31]. This finding has provided important information, suggesting that neutralizing antibodies against reovirus T1L and T2A will not affect the usage of reovirus $\mathrm{T} 3 \mathrm{D}$ as therapy in canine cancers.

In summary, there was no difference in the seroprevalence of the 3 reovirus serotypes in healthy dogs according to geographical distribution. However, exposure to reovirus infection increased with age and in dogs housed outdoor. Co-infection of various reovirus serotypes is not uncommon in dogs and depends on the exposure to the virus. Reovirus seropositivity in the healthy dog population is high and comparable to that of the human population. This study has provided a better understanding of the seroepidemiology of reovirus in dogs. On top of that, these data are essential in predicting the outcome of oncolytic virotherapy using reovirus in canine cancers.

\section{REFERENCES}

1. Berard, A. and Coombs, K. M. 2009. Mammalian reoviruses: propagation, quantification, and storage. Curr. Protoc. Microbiol. 15: Unit15C.1.

2. Binn, L. N., Marchwicki, R. H., Keenan, K. P., Strano, A. J. and Engler, W. F. 1977. Recovery of reovirus type 2 from an immature dog with respiratory tract disease. Am. J. Vet. Res. 38: 927-929. [Medline]

3. Buonavoglia, C. and Martella, V. 2007. Canine respiratory viruses. Vet. Res. 38: 355-373. [Medline] [CrossRef]

4. Csiza, C. K. 1974. Characterization and serotyping of three feline reovirus isolates. Infect. Immun. 9: 159-166. [Medline]

5. Decaro, N., Campolo, M., Desario, C., Ricci, D., Camero, M., Lorusso, E., Elia, G., Lavazza, A., Martella, V. and Buonavoglia, C. 2005. Virological and molecular characterization of a mammalian orthoreovirus type 3 strain isolated from a dog in Italy. Vet. Microbiol. 109: 19-27. [Medline] [CrossRef]

6. Fukumi, H., Takeuchi, Y., Ishida, M. and Saito, H. 1969. Serological epidemiology of reovirus infection. 1. Jpn. J. Med. Sci. Biol. 22: 13-21. [Medline]

7. Hirahara, T., Yasuhara, H., Matsui, O., Kodama, K., Nakai, M. and Sasaki, N. 1988. Characteristics of reovirus type 1 from the respiratory tract of pigs in Japan. Jpn. J. Vet. Sci. 50: 353-361. [Medline] [CrossRef]

8. Hwang, C. C., Umeki, S., Kubo, M., Hayashi, T., Shimoda, H., Mochizuki, M., Maeda, K., Baba, K., Hiraoka, H., Coffey, M., Okuda, M. and Mizuno, T. 2013. Oncolytic reovirus in canine mast cell tumor. PLOS ONE 8: e73555. [Medline] [CrossRef]

9. Kokubu, T., Takahashi, T., Takamura, K., Yasuda, H., Hiramatsu, K. and Nakai, M. 1993. Isolation of reovirus type 3 from dogs with diarrhea. J. Vet. Med. Sci. 55: 453-454. [Medline] [CrossRef]

10. Lerner, A. M., Cherry, J. D., Klein, J. O. and Finland, M. 1962. Infections with reoviruses. N. Engl. J. Med. 267: 947-952. [Medline] [CrossRef]

11. Lou, T. Y. and Wenner, H. A. 1963. Natural and experimental infection of dogs with reovirus type 1: pathogenecity of the strain for other animals. Am. J. Hyg. 77: 293-304.

12. Maitra, R., Ghalib, M. H. and Goel, S. 2012. Reovirus: a targeted therapeutic- progress and potential. Mol. Cancer Res. 10: 1514-1525. [Medline] [CrossRef]

13. Marshall, J. A., Kennett, M. L., Rodger, S. M., Studdert, M. J., Thompson, W. L. and Gust, I. D. 1987. Virus and virus-like particles in the faeces of cats with and without diarrhoea. Aust. Vet. J. 64: 100-105. [Medline] [CrossRef]

14. Massie, E. L. and Shaw, E. D. 1966. Reovirus type 1 in laboratory dogs. Am. J. Vet. Res. 27: 783-787. [Medline]

15. Matsuura, K., Hasegawa, S., Nakayama, T., Morita, O. and Uetake, H. 1984. Viral pollution of the rivers in Toyama City. Microbiol. Immunol. 28: 575-588. [Medline] [CrossRef]

16. Mochizuki, M. and Uchizono, S. 1993. Experimental infections of feline reovirus serotype 2 isolates. J. Vet. Med. Sci. 55: 469-470. [Medline] [CrossRef]

17. Murakami, T. and Kato, H. 1975. Reovirus antibody patterns in dogs: a trial for the application of principal component analysis to seroepidemiology. Natl. Inst. Anim. Health $Q$ (Tokyo) 15: 8-14. [Medline]

18. Muscillo, M., La Rosa, G., Marianelli, C., Zaniratti, S., Capobianchi, M. R., Cantiani, L. and Carducci, A. 2001. A new RT-PCR method for the identification of reoviruses in seawater samples. Water Res. 35: 548-556. [Medline] [CrossRef]

19. Osterhaus, A., Berghuis-De Vries, J. and Steur, K. 1977. Antiviral antibodies in dogs in the Netherlands. Zentralbl. Veterinärmed. B. 24: 123-133. [Medline] [CrossRef]

20. Ouattara, L. A., Barin, F., Barthez, M. A., Bonnaud, B., Roingeard, P., Goudeau, A., Castelnau, P., Vernet, G., Paranhos-Baccalà, G. and Komurian-Pradel, F. 2011. Novel human reovirus isolated from children with acute necrotizing encephalopathy. Emerg. Infect. Dis. 17: 1436-1444. [Medline]

21. Pal, S. R. and Agarwal, S. C. 1968. Sero-epidemiological study of reovirus infection amongst the normal population of the Chandigarh area- northern India. J. Hyg. (Lond.) 66: 519-529. [Medline] [CrossRef]

22. Rosen, L. 1960. Serologic grouping of reoviruses by hemagglutination-inhibition. Am. J. Hyg. 71: 242-249. [Medline]

23. Rosen, L. 1962. Reoviruses in animals other than man. Ann. N. Y. Acad. Sci. 101: 461-465. [Medline] [CrossRef]

24. Rosen, L., Abinanti, F. R. and Hovis, J. F. 1963. Further observations on the natural infection of cattle with reoviruses. Am. J. Hyg. 77: 38-48. [Medline]

25. Sabin, A. B. 1959. Reoviruses. Science 130: 1387-1389. [CrossRef]

26. Schiff, L. A., Nibert, M. L. and Tyler, K. L. 2007. Orthoreoviruses and their replication. pp. 1853-1915. In: Fields Virology, 5th ed. (Knipe, D. M. and Howley, P. M. eds), Lippincott Williams \& Wilkins, Philadelphia.

27. Scott, F. W., Kahn, D. E. and Gillespie, J. H. 1970. Feline viruses: isolation, characterization, and pathogenicity of a feline reovirus. Am. J. Vet. Res. 31: 11-20. [Medline]

28. Selb, B. and Weber, B. 1994. A study of human reovirus IgG and IgA antibodies by ELISA and western blot. J. Virol. Methods 47: 15-25. [Medline] [CrossRef]

29. Tai, J. H., Williams, J. V., Edwards, K. M., Wright, P. F., Crowe, J. E. J. and Dermody, T. S. 2005. Prevalence of reovirus-specific 
antibodies in young children in Nashville, Tennessee. J. Infect. Dis. 191: 1221-1224. [Medline] [CrossRef]

30. Tani, N., Dohi, Y., Kurumatani, N. and Yonemasu, K. 1995. Seasonal distribution of adenoviruses, enteroviruses and reoviruses in urban river water. Microbiol. Immunol. 39: 577-580. [Medline] [CrossRef]

31. Taylor-Robinson, D. 1965. Respiratory virus antibodies in human sera from different regions of the world. Bull. World Health Org. 32: 833-847. [Medline]
32. Weiner, H. L. and Fields, B. N. 1977. Neutralization of reovirus: the gene responsible for the neutralization antigen. J. Exp. Med. 146: 1305-1310. [Medline] [CrossRef]

33. White, C. L., Twigger, K. R., Vidal, L., De Bono, J. S., Coffey, M., Heinemann, L., Morgan, R., Merrick, A., Errington, F., Vile, R. G., Melcher, A. A., Pandha, H. S. and Harrington, K. J. 2008. Characterization of the adaptive and innate immune response to intravenous oncolytic reovirus (Dearing type 3) during a phase I clinical trial. Gene Ther. 15: 911-920. [Medline] [CrossRef] 